\title{
Scenes from a Marriage: On the confrontation model of history and philosophy of science
}

\author{
Raphael Scholl*
}

Draft of January 23, 2018

\begin{abstract}
According to the "confrontation model," integrated history and philosophy of science operates like an empirical science. It tests philosophical accounts of science against historical case studies much like other sciences test theory against data. However, the confrontation model's critics object that historical facts can neither support generalizations nor genuinely test philosophical theories. Here I argue that most of the model's defects trace to its usual framing in terms of two problematic accounts of empirical inference: the hypotheticodeductive method and enumerative induction. This framing can be taken to suggest an unprofitable one-off confrontation between particular historical facts and general philosophical theories. I outline more recent accounts of empirical inquiry, which describe an iterative back-and-forth movement between concrete (rather than particular) empirical exemplars to their abstract (rather than general) descriptions. Reframed along similar lines, the confrontation model continues to offer both conceptual insight and practical guidance for a naturalized philosophy of science.
\end{abstract}

(Forthcoming in The Journal of the Philosophy of History.)

${ }^{*}$ Department of History and Philosophy of Science, University of Cambridge, Cambridge CB2 3RH, UK, e-mail: ras223@cam.ac.uk 


\section{Introduction}

How do philosophical accounts of science relate to the history of science? Since roughly the 1980s, many practitioners of integrated history and philosophy of science (or HPS) have espoused a close analogy to the natural sciences: They have framed HPS as an empirical science of science. On this view, philosophers of science articulate hypotheses about science and test them against historical case studies, much like scientists test hypotheses about nature against data from observation and experiment. In an insightful review of recent debates concerning the history-philosophy relationship, Jutta Schickore dubbed this the "confrontation model" of HPS. ${ }^{1}$

The confrontation model is attractive because it solves conceptual and practical problems of the history-philosophy relationship. Consider, for example, how the model elucidates the nature and status of philosophical analyses of science. The positivist tradition of the mid-twentieth-century wanted philosophy to provide autonomous normative guidance to the sciences but found it difficult to make good on that ambition. The confrontation model, by contrast, suggests an empirical project that is continuous with science itself and needs no autonomous warrant. Moreover, the confrontation model provides practical guidance. It suggests that progress in the philosophy of science requires us to break down our accounts into their components parts, and to articulate each part with sufficient clarity to permit empirical testing against contemporary and historical scientific practice. Proponents of the confrontation model would point to many debates in the past decades (for example on induction, explanation, or scientific realism) whose progress has relied on such empirical testing.

Despite its attractions, the confrontation model has faced severe criticisms. For one thing, how can historical facts provide evidence for or against philosophical theses? Many believe that historical data resists generalization, is heavily theory-laden, and lacks normative force. For another thing, does the history of science even provide appropriate data against which philosophers can test their theses? Historians may not be investigating the details of epistemic practices, for example, that are relevant to philosophers. Finally, is it self-defeating to link history and philosophy of

1. Jutta Schickore, "More Thoughts on HPS: Another 20 Years Later," Perspectives on Science 19, no. 4 (2011): 453-481. Schickore's title was a reply to Larry Laudan, "Thoughts on HPS: 20 Years Later," Studies in History and Philosophy of Science Part A 20, no. 1 (1989): 9-13. 
science as data and theory? Perhaps an empirical philosophy of science most naturally and profitably engages not with the history of science, but with recent science and the empirical disciplines that study recent science.

The thesis of the present article is that the confrontation model's difficulties are artifactual. The problem is not that the basic analogy between HPS and the empirical sciences is unsound. Instead, the model's problems can be traced to its usual framing in terms of two influential but problematic accounts of empirical inquiry: hypothetico-deductivism and enumerative induction. I will argue that most objections against the model disappear if we adopt an updated view of empirical inquiry that is closely informed by recent studies of the life sciences.

Section 2 begins by outlining the attractions of the confrontation model, while section 3 discusses the objections against it. Section 4 then reframes the analogy between the methodology of HPS and the methodology of the empirical sciences. Section 5 revisits the difficulties, arguing that the reframing of the confrontation model resolves or ameliorates them. Section 6 concludes the discussion.

\section{Attractions of the confrontation model}

The confrontation model emerged as a consequence of a larger shift in philosophers' thinking about the history-philosophy relationship. To situate the shift in conceptual space, consider a contribution by David Hull to a symposium at the 1992 meeting of the Philosophy of Science Association. ${ }^{2}$ He suggested a two-by-two matrix of views about the role of empirical evidence in science, on the one hand, and in the study of science, on the other. First, there was the logical empiricist tradition, dominant in midtwentieth-century philosophy of science, which took empirical evidence to be crucial in science, but assumed that philosophical claims about science must be supported by extra-empirical, a priori standards. The second position was to believe that empirical evidence is not decisive in science itself, but that it should have a greater role in deciding between different philosophical accounts. An odd view at first glance, this was plausibly Thomas

2. David L. Hull, "Testing Philosophical Claims About Science," PSA: Proceedings of the Biennial Meeting of the Philosophy of Science Association, 1992, 468-475. 
Kuhn's position in The Structure of Scientific Revolutions. ${ }^{3}$ Third, there were relativists who denied that empirical evidence has a decisive role either in science or in the study of science. And finally, there were those who thought that empirical evidence is crucial both to science and to the study of science. Hull committed to the fourth view:

We need to construct theories about science the way that scientists construct theories about fluids, gene flow and continental drift. To construct such theories, we need data, and our only source of data is the study of science, past and present. ${ }^{4}$

Like Hull, many philosophers of science in the 1980s transitioned from the first to the fourth position. I will refer to these as the "a priori" and the "naturalistic" positions, respectively. While the details of the accounts differed, a naturalistic view of the project of the study of science came to be widely adopted. ${ }^{5}$

Why did philosophers change their minds about the relationship between philosophical claims and empirical evidence? A large part of the answer is that the a priori position was perceived to have run out of steam. This is nicely exemplified by two contributions, twelve years apart, by Ronald Giere.

In 1973, Giere famously asked whether the history and philosophy of science were in an "intimate relationship" or a mere "marriage of convenience." ${ }^{\prime 6}$ At the time, he judged that proponents of the intimate relationship had failed to make their case. One problem was circularity: If we wish to use historical facts as evidence in our philosophical theorizing about science's empirical methods, this presupposes that we already have some notion of evidence - that is, of empirical methods. This circularity suggests that at least some empirical methods cannot be discovered empirically. Another problem was normativity: It was widely accepted that the aim of philosophy was not just to describe science's empirical methods, but to make

3. Thomas Kuhn, The Structure of Scientific Revolutions (University of Chicago Press, 1962).

4. Hull, "Testing Philosophical Claims About Science," 473.

5 . On the reemergence of varieties of naturalism in the second half of the twentieth century, see Philip Kitcher, "The Naturalists Return," The Philosophical Review 101, no. 1 (1992): 53-114.

6. Ronald N. Giere, "History and Philosophy of Science: Intimate Relationship or Marriage of Convenience?," The British Journal for the Philosophy of Science 24 (1973): 282-297. 
normative judgments about their validity. It was reasonably clear how a priori approaches could support such prescriptions. For instance, Popper's falsificationism, which claimed that inferences from particular facts to general theories are only valid if they instantiate modus tollens, derived its normative force from deductive logic. But the naturalistic approaches could not rely on the authority of deductive inference. They had to provide "a philosophical account which explains how norms are based on facts."7 Such an account remained to be articulated, although Giere did not rule out the possibility that one might eventually be found.

By 1985, Giere's assessment of the situation had changed. ${ }^{8}$ He now argued that existing a priori approaches had failed. In particular, Giere identified fundamental flaws in methodological foundationism: the project of giving a priori justifications for empirical methods. This included Carnap's inductive logic, Reichenbach's "straight rule," Popper's falsificationism, and variants of Bayesianism. All of these proposals faced both conceptual and empirical difficulties, and Giere argued that they could not resolve them without resorting to empirical facts. They avoided circularity no more successfully than their naturalistic rivals. Giere thus judged methodological foundationism to be "a hopeless program" that could not justify methodological norms. ${ }^{9}$ What is more, the a priori approaches had failed to give even remotely adequate descriptions of actual scientific reasoning. On balance, the naturalized approach to the philosophy of science now seemed to offer the best prospects. Giere concluded that "the study of science must itself be a science," and that the "only viable philosophy of science is a naturalized philosophy of science." 10

The naturalized approach permits a reassessment of the problems of circularity and normativity. Abandoning the assumption that there must be a foundational scientific method with a priori warrant, naturalism expects that the justification of empirical claims will rely on further empirical claims. Nevertheless, the problem of circularity is defanged, since the justifying claims, although empirical, are different in content from the justified claims. As Giere put it succinctly some decades later, "inquiry always be-

7. Giere, “Intimate Relationship or Marriage of Convenience?," 290.

8. Ronald N. Giere, "Philosophy of Science Naturalized," Philosophy of Science 52, no. 3 (1985): 331-356.

9. Ibid., 336.

10. Ibid., 355. 
gins with the beliefs one has," and "anything can be questioned, but not everything at once."11 The naturalized approach transforms the problem of scientific knowledge. The task is no longer to give a foundational justification for scientific methods. Instead, the demand is for a scientific explanation. How are organisms with roughly our biological makeup, possessing roughly our capacities for perception and cognition, and living in roughly the environment we find ourselves in, capable of learning about the detailed structure of the world?

Despite the turn away from the a priori tradition, naturalistic philosophers tried to recover a lean notion of goal-relative normativity. ${ }^{12}$ Physics is indisputably an empirical discipline, but it does tell us what we "should" do in order to achieve particular purposes such as sending probes to distant planets. The philosophy of science can similarly investigate which procedures promote desired goals. ${ }^{13}$ In this spirit, Hull even suggested that we test proposed norms experimentally by convincing groups of scientists to adopt them:

If science in such areas immediately grinds to a halt, then possibly something is wrong with one's normative claims. Conversely, if those scientists who adopt your views are even more successful in attaining their epistemic goals, then possibly there is something to be said for these norms. ${ }^{14}$

Naturalists must argue that it is cogent to test empirical methods empirically. ${ }^{15}$

The confrontation model is a corollary to the shift to naturalism. If philosophical accounts of science have the same status as scientific theories, then they must be submitted to similarly stringent empirical tests. The most ambitious and best-known effort in that direction was the Virginia Polytechnic Institute (VPI) project on scientific change. Under the direction

11. Ronald N. Giere, "History and Philosophy of Science: Thirty-Five Years Later," in Integrating History and Philosophy of Science, ed. Seymour Mauskopf and Tad Schmaltz (Springer, 2011), 61.

12. Ibid.

13. Larry Laudan, "Progress or Rationality? The Prospects for Normative Naturalism," American Philosophical Quarterly 24, no. 1 (1987): 19-31.

14. Hull, "Testing Philosophical Claims About Science," 474.

15. Peter Lipton and John Worrall, "Tracking Track Records," Proceedings of the Aristotelian Society, Supplementary Volumes 74 (2000): 179-235. See also Kitcher, "The Naturalists Return." 
of Larry Laudan, Rachel Laudan and Arthur Donovan, the project's goal was to articulate influential "post-positivist" accounts of scientific change by such authors as Kuhn, Lakatos, and Laudan himself - in terms of historically testable theses. ${ }^{16}$ Providing empirical support for these models was seen in direct contrast to the "logical or philosophical ideals of epistemic warrant" that an earlier generation of philosophers had insisted upon. ${ }^{17}$ But so far, few assertions about the nature and dynamics of science were well-founded by naturalistic standards. The post-positivist models of scientific change had received only "perfunctory and superficial" testing and had met "[n]othing resembling the standards of testing that these very authors insist upon within science."18 It was time to go beyond "[s]loganeering on behalf of naturalism in epistemology" and to address the "particularities of the testing process itself." 19

To the best of my knowledge, no one ever produced a handbook on naturalistic theory testing in philosophy that discussed those particularities of the testing process in depth. However, among the steps that the VPI group took in order to render models of scientific change testable, two in particular stand out. First, the models needed to be teased apart into separate claims that could be assessed individually, since all models were likely false if judged in their entirety. In a field marked by competing big pictures, this promised progress by modularization. Second, claims needed to be made empirically tractable. They needed to be operationalized so that empirical data could support or rebut them. Hull even argued compellingly that the only way to fully articulate the content of many philosophical theses about science is to operationalize them. ${ }^{20}$

16. Larry Laudan et al., "Scientific Change: Philosophical Models and Historical Research," Synthese 69, no. 2 (1986): 141-223, and Arthur Donovan, Larry Laudan, and Rachel Laudan, eds., Scrutinizing Science: Empirical Studies of Scientific Change (Kluwer Academic Publishers, 1988). For a recent reflection on the project by two main authors, see Larry Laudan and Rachel Laudan, "The Re-Emergence of Hyphenated History-and-Philosophyof-Science and the Testing of Theories of Scientific Change," Studies in History and Philosophy of Science Part A 59 (2016): 74-77.

17. Laudan et al., "Scientific Change," 142.

18. Ibid.

19. Ibid., 143.

20. David Hull, "Studying the Study of Science Scientifically," Perspectives on Science 6, no. 3 (1998): 209-231. 


\section{Objections to the confrontation model}

In her recent survey of debates about HPS, Schickore questioned whether the analogy between the empirical sciences and HPS is appropriate and useful. ${ }^{21}$ In her view, the difficulties of the confrontation model are overwhelming, and practitioners of HPS would do better to understand themselves as part of a hermeneutic tradition.

The first two worries, and in my view the most important, concern the way in which historical episodes can be expected to speak for or against philosophical theses. One problem is summarized by what Joseph Pitt has called the "dilemma of case studies." His abstract is a concise thesis statement:

What do appeals to case studies accomplish? Consider the dilemma: On the one hand, if the case is selected because it exemplifies the philosophical point, then it is not clear that the historical data hasn't been manipulated to fit the point. On the other hand, if one starts with a case study, it is not clear where to go from there - for it is unreasonable to generalize from one case or even two or three. ${ }^{22}$

The dilemma's two horns are the following. If we work "top-down," we begin with a general philosophical hypothesis and look for particular historical cases to test it. But then how do we know that we are not imposing a preconceived philosophical view on the evidence, either by selecting convenient cases or by distorting inconvenient ones? We are no better off if we reason "bottom-up," beginning with particular historical cases and trying to derive general philosophical hypotheses from them. For then we are immediately confronted with a basic difficulty of induction: How many cases are sufficient warrant for a general claim?

Another problem is that historical data is suspected to be theory-laden and cannot unproblematically serve to test philosophical theories. If the historical data is itself shaped by philosophical assumptions, then using it to test philosophical theories may be viciously circular. According to Schickore, the debates about theory-ladenness were never brought to a con-

21. Schickore, "More Thoughts on HPS."

22. Joseph C. Pitt, "The Dilemma of Case Studies: Toward a Heraclitian Philosophy of Science," Perspectives on Science 9, no. 4 (2001): 373. 
clusion. ${ }^{23}$ For many there remain serious doubts about whether historical data is sufficiently independent to adjudicate philosophical debates. ${ }^{24}$

The third problem is that the history of science may simply not provide the kind of data that philosophers require. Schickore considered recent winners of the Pfizer Award of the History of Science Society. These works reveal the concern of present-day historians of science with visual representations; with the role and influence of nominally non-scientific actors (from gardeners to midwives and engineers) on the history of science; or with the role of commerce in scientific exchanges in the early modern period. ${ }^{25}$ But they do not obviously speak to the concerns of philosophers.

Fourth, Schickore argued that a naturalistic construal of the historyphilosophy relationship may be self-defeating. ${ }^{26}$ If philosophical claims are to be tested by confrontation with an empirical basis, why should that basis be the history of science? Giere had already suggested that disciplines studying contemporary science - sociology, cognitive science, and so on - may provide a more appropriate and richer empirical basis for testing philosophical claims about science.

Given the cumulative force of these difficulties, two options present themselves. One is to question the viability of HPS as a metascientific project. The other is to identify the source of the difficulties and to reframe the HPS project in more productive terms. This is what Schickore chose to do:

The problem is the confrontation model, which portrays philosophical analysis as akin to the practice of natural science, as a practice of constructing a general theory, producing data, and confronting the theory with the data. This portrayal misrepresents the nature of analyses of science. ${ }^{27}$

She argued that one could not simply work bottom-up by generalizing from the phenomena "because one will need some preliminary concepts to

23. Schickore, "More Thoughts on HPS," 467.

24. For recent discussions, see Katherina Kinzel, "Narrative and Evidence. How Can Case Studies from the History of Science Support Claims in the Philosophy of Science?," Studies in History and Philosophy of Science Part A 49 (2015): 48-57; Katherina Kinzel, "Pluralism in Historiography: A Case Study of Case Studies," in The Philosophy of Historical Case Studies, ed. Tilman Sauer and Raphael Scholl (Springer, 2016), 123-149.

25. Schickore, "More Thoughts on HPS," 465-6.

26. Ibid., 470.

27. Ibid., 471. 
examine the historical record." ${ }^{28}$ Nor could one reason top-down by testing preconceived philosophical accounts, since "the examination of the historical record will affect the initial analytic tools." 29

Schickore instead suggested a hermeneutic conception of HPS. ${ }^{30}$ It recognizes that "philosophical and indeed any analyses of science can only be obtained through acts of interpretation," and that "the initial interpretive categories are necessarily provisional." ${ }^{\prime 31}$ Our conception of HPS must reflect that the student of science moves in an interpretive circle:

Initial case judgments - judgments that identify portions of the historical record as noteworthy - and provisional analytic concepts are gradually reconciled until they are brought into equilibrium. To characterize this metascientific endeavor in terms of "case studies" that are "confronted" with "general philosophical accounts" is misleading. ${ }^{32}$

Thus, HPS is an iterative activity that seeks an equilibrium between philosophical concepts and interpretations of historical cases. It is far removed from the notion of a decisive one-off confrontation between theory and data. Schickore thus concluded that HPS should not be construed as a science of science.

In the next two sections, I will take a different tack. I grant many of the criticisms that Schickore cites, but I believe that she has misdiagnosed the problem. The analogy between science and the philosophy of science is sound. The problem is that we have framed the confrontation model in terms of two inadequate accounts of empirical inquiry in the natural sciences. Most of the model's difficulties can be traced to this framing, including the notion of decisive one-off confrontations. If we update our account of empirical inquiry, then the objections to the confrontation model largely dissolve. This allows us to improve our understanding of the history-philosophy relationship while also retaining the many virtues of a naturalized philosophy of science.

28. Schickore, "More Thoughts on HPS," 472.

29. Ibid.

30. C. Mantzavinos, "Hermeneutics," in The Stanford Encyclopedia of Philosophy, Winter 2016, ed. Edward N. Zalta (Metaphysics Research Lab, Stanford University, 2016).

31. Schickore, "More Thoughts on HPS," 461.

32. Ibid., 471 . 


\section{Reframing the confrontation model}

The confrontation model's usual framing relies explicitly or implicitly on two accounts of empirical inquiry: hypothetico-deductivism and enumerative induction. The model thus inherits the defects of these accounts, and this motivates Pitt's dilemma of case studies. ${ }^{33}$

One horn of the dilemma assumes that we work top-down from general philosophical accounts to particular cases. But then the dangers are analogous to some worries about hypothetico-deductive theory-testing. The sample by which we test our theory may be incomplete or biased. Our testing of the hypothesis that "all swans are white" will be misleading if, by happenstance or ill will, the sample against which we test the hypothesis does not contain those swans that are black. The other horn of the dilemma assumes that we work bottom-up from particular cases to general philosophical accounts. The dangers are then analogous to those of enumerative induction: No matter how many observations of white swans there are in our premises, the conclusion that all swans are white is not guaranteed.

In philosophical debates of the 20th century, enumerative induction mainly served a didactic purpose. It represented an implausible, narrow conception of induction. This was then contrasted with the more powerful hypothetico-deductive account. ${ }^{34}$ However, scholarship over the past decades suggests that, in many cases, neither model is a good description of actual empirical inquiry.

In particular, recent work in the philosophy of biology suggests that biological practice rarely involves the framing of general hypotheses which are then tested by their particular deductive consequences. Instead, the focus is on elucidating mechanisms: detecting and isolating their components, determining how the components interact, and understanding how components and interactions are organized to produce a range of phenomena. ${ }^{35}$ We will see that the mechanistic accounts of empirical inquiry bring

33. A summary of the strengths and weaknesses of different accounts of induction is given by John D. Norton, "A Little Survey of Induction," in Scientific Evidence: Philosophical Theories $\mathcal{E}$ Applications, ed. Peter Achinstein (Baltimore \& London: The Johns Hopkins University Press, 2005).

34. See for instance Chapter 2 in Carl G. Hempel, Philosophy of Natural Science (Prentice Hall, 1966).

35. William Bechtel and Robert C. Richardson, Discovering Complexity: Decomposition and Localization as Scientific Research Strategies (Princeton University Press, 1993); Peter Machamer, Lindley Darden, and Carl F. Craver, "Thinking About Mechanisms," Philosophy 
different conceptual issues to the fore than the traditional models.

To be sure, there are vast differences between mechanistic research in biology, on the one hand, and HPS, on the other. Nevertheless, I will argue that some conceptual insights about the character of empirical inquiry are transferable between the two. Three caveats, however, are in order. First, there is no need for present purposes to commit to any of the details of the various accounts of biological mechanisms, or to decide how widely they apply to biology (let alone to other disciplines). These issues remain controversial in the literature. What matters is that even the broad outline of empirical reasoning that these accounts offer is quite different from the models of inquiry that discussions of the history-philosophy relationship usually presuppose. Second, my claim is not that the comparison to biology is uniquely insightful. While empirical inquiry in biology has been particularly thoroughly studied and provides us with the resources we need for reframing the confrontation model, a close look at other empirical disciplines may reveal similar procedures. Third, I am not arguing that hypothetico-deductivism is altogether outdated. Especially in its more recent articulation as Inference to the Best Explanation (IBE), hypotheticodeductivism remains a widespread proposal in scientific epistemology. The claim here is only that some empirical inquiry is best understood in different terms. ${ }^{36}$

Let us turn to a description of mechanistic inquiry in biology. In the terminology of Bechtel and Abrahamsen, mechanistic research often proceeds from the study of "prototypes" or "exemplars." ${ }^{37}$ In the biological context, these are called model organisms. For instance, the mechanisms of neural transmission were extensively studied using the giant axon of the squid, since its size was amenable to study by the available instruments and techniques. Oxidative phosphorylation was studied using mitochondria from the hearts of cows, since this is an easily obtainable tissue

of Science 67, no. 1 (2000): 1-25; William Bechtel, Discovering Cell Mechanisms: The Creation of Modern Cell Biology (Cambridge University Press, 2006); Lindley Darden, Reasoning in Biological Discoveries: Essays on Mechanisms, Interfield Relations, and Anomaly Resolution (Cambridge University Press, 2006); Carl F. Craver and Lindley Darden, In Search of Mechanisms: Discoveries Across the Life Sciences (University of Chicago Press, 2013).

36. The case against the centrality of IBE in biological inquiry is made in Aaron Novick and Raphael Scholl, "Presume It Not: True Causes in the Search for the Basis of Heredity," The British Journal for the Philosophy of Science, forthcoming.

37. William Bechtel and Adele Abrahamsen, "Explanation: A Mechanist Alternative," Studies in History and Philosophy of Biological and Biomedical Sciences 36, no. 2 (2005): 438. 
with abundant mitochondria. The goal of such research is not to articulate the kinds of laws, understood as universally valid statements, that the hypothetico-deductive model sets out to test. Instead, the investigation of a mechanism requires techniques and procedures for detecting, isolating, and manipulating mechanism components in order to determine their interactions and their organization. Bechtel and Richardson referred to this as the structural and functional "decomposition" of a mechanism. ${ }^{38}$ Structural and functional decomposition can proceed in any order, but usually they will happen in parallel: as we identify parts, we can also test what operations they perform. When an operation is mapped to a part, Bechtel and Richardson call this "localization." Decomposition and localization result in a description of a mechanism in the particular organism and context under study.

Eventually scientists wish to assess the generality of their findings. On traditional accounts, generalization is "automatic," to quote Bechtel and Abrahamsen. ${ }^{39}$ If we take a general law to be supported by the available evidence, then it automatically applies to all cases in which specified antecedent conditions are satisfied. By contrast, the mechanistic approach aims for a different kind of generality. It consists in examining whether and to what extent the mechanisms described in one case operate in a range of further cases:

The challenge for understanding generalization is that a mechanistic account is highly particularized: researchers develop it for a model organism and study mechanisms in model organisms, and it is anticipated that there will be important differences - involving parts, operations, and organization - between already-studied organisms and those to which a scientist wishes to generalize a mechanistic explanation. ${ }^{40}$

To capture this type of generalization, the notion of a mechanism schema is useful. Mechanism schemas are "abstract descriptions of a mechanism with placeholders that can be filled in with known entities and activities."41

38. Bechtel and Richardson, Discovering Complexity.

39. Bechtel and Abrahamsen, "Explanation: A Mechanist Alternative," 437.

40. William Bechtel, "Generalization and Discovery by Assuming Conserved Mechanisms: Cross-Species Research on Circadian Oscillators," Philosophy of Science 76, no. 5 (2009): 763.

41. Craver and Darden, In Search of Mechanisms, 7. 
When scientists examine the generality of a mechanism, they investigate whether a particular abstract mechanism schema is widely instantiated by concrete organisms. Craver and Darden have referred to this as a schema's "scope." 42 The mark of generality of a biological mechanism is that its schema has broad scope. Its generality increases with the number of further instances of the mechanism schema in other members of the same species, in closely related species, and sometimes even in distantly related ones.

The partial view of empirical inquiry that I have outlined can be summarized in terms of three operations. The first operation is to study an exemplar or a set of exemplars in order to describe concrete mechanisms. The second operation is to articulate an abstract description of these mechanisms, the mechanism schema. The third operation is to examine the abstract description's scope: how widely it applies to other cases. The fact that we have already developed the account in one concrete case will be a great heuristic help in checking whether, and to what extent, it can be transferred to others. These operations are recurrent steps in an iterative process.

The three operations do not constitute a conceptual or temporal succession. This is important in particular for the first and second operations, since any concrete description will always require certain abstract categories that precede it. If we have no abstract notion of what a "cell" is, then we cannot describe anything as a cell. Moreover, it will sometimes perhaps commonly - happen that the phenomenon we initially took to be significant is not the same phenomenon that we will end up explaining. For instance, as the mechanism of gene expression was elucidated between the late nineteenth and mid-twentieth centuries, scientists repeatedly revised their notion of what was expressed. Mendel and Morgan thought of genes in terms of the expression of traits; Beadle and Tatum took genes to express enzymes; by the time of Jacob and Monod, genes were taken to express both regulatory and structural proteins. Bechtel and Richardson wrote of "reconstituting the phenomena" to capture this aspect of empirical inquiry. ${ }^{43}$

Notice that two different pairs of antonyms appear in the preceding paragraphs. In the traditional accounts, we test "general" hypotheses against

42. Craver and Darden, In Search of Mechanisms, 35.

43. Bechtel and Richardson, Discovering Complexity, Ch. 8. 
"particular" facts. In the revised account, the movement is from "concrete" instances to "abstract" descriptions. The former invites problems that the latter avoids. In the traditional framing in terms of the particular and the general, the crucial inferences are taken to be ampliative in the sense that the content of the general conclusion of our inference goes beyond the content of its particular premises. Observations of a limited set of entities ("a hundred ravens were black") are taken to support claims about all such entities ("all ravens are black"). The traditional debates about models of induction are concerned with understanding how this amplification of content can be justified. By contrast, the transition from the concrete to the abstract brackets the problem of ampliative inference. In articulating an abstract description and examining whether it applies to further concrete instances, we are not amplifying the content of our observational premises. We are merely charting the range of applicability of an abstract description.

This is not to say that ampliative inferences are irrelevant in biology. For instance, biological models make assertions about the causal relationships between mechanism components under specified conditions. To the extent that this is supposed to apply to similarly situated components that have not yet been studied, the claim is ampliative. Whether it is warranted will depend on the applicability of the assumptions underlying the relevant causal inferences and extrapolations. Similarly, biologists routinely assume that the mechanisms discovered in one organism operate in comparable ways (although perhaps not identically) in closely related organisms. This can also be construed as an ampliative inference, one whose reliability depends on the relevant assumptions about phylogenetic relatedness and evolutionary conservation. Certainly we must closely examine the nature and warrant of such ampliative inferences. ${ }^{44}$ However, the issue of ampliative inference is largely orthogonal to routine empirical inquiry in the framework of the three-operation model.

I submit that the three-operation model of empirical inquiry is also applicable to the study of science. Just like biologists, historians and philosophers of science often proceed from exemplars in the history of science. These are usually called case studies. They then move between concrete

44. My view is that these kinds of ampliative inferences rely on material postulates in the sense of John D. Norton, "A Material Theory of Induction," Philosophy of Science 70, no. 4 (2003): 647-670. 
and abstract descriptions of aspects of the cases, rather than between particular claims and general theses. ${ }^{45}$ The aim is to provide abstract models of salient scientific practices. Topics will include traditional philosophical interests like induction, experiment, and explanation, but also more recent philosophical interests like consensus formation, diagrammatic practices, or as yet uncharted areas. Much of this work will be concerned with developing accurate concrete descriptions of the exemplars. These will then inform the articulation of corresponding abstract models. When we have succeeded in articulating such abstract models, the next step is not to conclude that a model that worked in one case (or two or three cases) is generally applicable. The model is merely a tool we have at our disposal for elucidating further concrete episodes. It will ideally lead to the discovery of both similarities and differences to the cases already studied. Such renewed "confrontations" will allow us to improve our abstract models by refining, adding, or removing components. ${ }^{46}$ Although generalization remains a goal, it consists in the examination of the empirical scope of our abstract descriptions: How broad is the range of further concrete cases to which the same descriptions apply? This process does not consist in a oneoff confrontation between theory and data. It is iterative and will frequently require us to reconstitute the phenomena as we proceed. Explanans and explanandum will evolve together over time.

\section{Revisiting the objections}

It is time to revisit the objections discussed in Section 3 in light of the reframed confrontation model outlined in Section 4.

\subsection{The dilemma of case studies}

The three-operation model of empirical inquiry mitigates or even dissolves Pitt's dilemma of case studies, and it is worth discussing in detail how it

45. That empirical inquiry in HPS moves between the concrete and the abstract, rather than between the particular to the general, was suggested to me by Hasok Chang, "Beyond Case-Studies: History as Philosophy," in Integrating History and Philosophy of Science, ed. Seymour Mauskopf and Tad Schmaltz (Springer, 2011), 109-124.

46. The dynamics of the piecemeal improvement of philosophical accounts of science are examined in Raphael Scholl and Tim Räz, "Towards a Methodology for Integrated History and Philosophy of Science," in The Philosophy of Historical Case Studies, ed. Tilman Sauer and Raphael Scholl (Springer, 2016), 69-91. 
does so. ${ }^{47}$

First, no part of the three-operation model involves enumerative induction. Let us say we begin by giving a description of one or more concrete cases of scientific explanation. We may, for instance, report that scientists explain the phenomenon of RNA splicing by describing how it is achieved by the so-called spliceosome: a dynamical complex of small nuclear RNAs and proteins that assemble on pre-mRNA and, by a complicated sequence of interactions, remove intronic sequences. So far, this concrete description involves no enumerative induction. Second, we will describe this type of scientific explanation more abstractly as "mechanistic," since these scientists explain the phenomenon of interest by describing the system's parts, their interactions, and their organization. In giving such an abstract description of a type of explanation, there is again no enumerative induction involved. We are merely reformulating our previous concrete description ("the U2 snRNP base-pairs to the branch point on the pre-mRNA") with placeholders instead of specific detail ("the parts $\mathrm{P}$ and $\mathrm{Q}$ interact by a known activity $\mathrm{R}^{\prime \prime}$ ). There is no claim here, for example, that scientific explanations are mechanistic "in general" - say, regardless of historical period or scientific discipline. This question only comes into focus with the third operation, when we ask about the scope of our abstract description. Do other concrete explanations also fit the abstract description of a mechanistic explanation? If so, in what time periods are these prominent, in which sciences, and in which circumstances? On the answers to these questions will depend our judgment of the relative significance of mechanistic explanations. Notice again, however, that there is still no enumerative induction involved. Enumeration, yes: We study how many other cases fit a given abstract description. But no induction in the sense of ampliative inference: We do not conclude that the abstract description is "general," except in so far as it has, as an empirical matter, a broad range of known instances.

Second, the three-operation model does not share the defects of the hypothetico-deductive model. Consider the danger of selection bias. If one's hypothesis about scientific explanation were that all explanations are mechanistic, then it would be easy to create spurious support for the posi-

47. See also Richard M. Burian, "The Dilemma of Case Studies Resolved: The Virtues of Using Case Studies in the History and Philosophy of Science," Perspectives on Science 9, no. 4 (2001): 383-404. 
tion by proffering cases that fit the mechanistic model well, while ignoring or explaining away other, less favorable cases. However, on the three-operation model we do not use historical evidence in this way. Concrete descriptions (obtained in operation one) are used only to derive abstract descriptions (operation two) and to determine the empirical scope of those abstract descriptions (operation three). The model never advises us to leverage individual concrete descriptions, or even a handful of them, in order to infer the generality of a philosophical thesis. We would have to provide additional warrant for such an extrapolation.

One upshot of the three-operation model is that the distinction between working top-down or bottom-up is somewhat beside the point in HPS. It does not matter much whether we begin by studying individual cases or by articulating abstract conceptions. The elements of the three-operation model need not be approached in a preset order. Sometimes the cases will suggest abstract conceptions to us which we will then elaborate. At other times, we will begin with certain preconceived abstract descriptions and see whether they fit a range of historical cases. Both approaches serve the same iterative process of aligning our abstract models with concrete historical episodes. Thus, the kind of gradual reconciliation of concepts and phenomena that Schickore took to be a hallmark of an interpretive, hermeneutic methodology is also a feature of the updated confrontation model. ${ }^{48}$

As in the case of biology, the claim here is not that ampliative inferences are wholly irrelevant to inquiry in HPS. For example, practitioners of HPS will often assume that what they learned about scientific practice in one case study is likely to apply to other cases. However, these are not instances of simple enumerative induction, or of testing hypotheses by their deductive consequences. Such extrapolations rely instead on the assumption that the cases in question are appropriately related. This is similar to extrapolations from model to target organisms in biology, which rely on facts about shared ancestry. In HPS, extrapolations are sometimes warranted by the fact that scientific practices in different cases are comparably related, albeit by different processes: by teaching and imitation. Few scientists invent their experimental, explanatory, or other practices de novo. So

48. See also C. Mantzavinos, “Text Interpretation as a Scientific Activity,” Journal for General Philosophy of Science 45, no. 1 (2014): 45-58. Mantzavinos argues that interpretive, hermeneutic methodology and scientific methodology are more alike than is commonly appreciated. 
it makes sense to extrapolate findings, cautiously, within recognizable scientific traditions. ${ }^{49}$ Importantly, however, such ampliative inferences often serve only as heuristics that guide the subsequent investigation of further cases. The expectation is that both similarities and dissimilarities to previously studied cases will be found. ${ }^{50}$

\subsection{The theory-ladenness of historical data}

Even if the problems of unwarranted generalization and of selection bias can be avoided, we must still worry about other ways in which we impose philosophical concepts on historical case studies. A prominent danger is the theory-ladenness of historical data: If we already have in mind some particular philosophical notions about science, does this not shape what we take to be the historical "data"? ${ }^{51}$ Many cases may turn out to look as if they were instances of our philosophical concepts simply because that is how we articulated them in the first place. The worry, in brief, is a traditional concern about inductive methods: that theory and data may not be independent of each other.

Sometimes this worry is equated with the problem of selection bias. Laudan and co-authors, for example, discuss the theory-ladenness of historical data as the worry that "the historians or scientists who might construct the relevant case studies are not 'neutral' parties, but will themselves bring certain prior theoretical assumptions of their own to the selection of data for inclusion in the analysis." 52 If this is all that the theory-ladenness of historical data amounts to, then the problem collapses with the problem of selection bias discussed in Section 5.1. The appropriate response is to stress that our inquiries do not, in fact, leverage particular facts to support general theses, contrary to traditional models of ampliative inference.

A more insidious version of the problem goes beyond selection bias, but its precise nature is difficult to articulate. The general fear is that the categories we hold while reading and writing history will make our narratives

49. The thesis that extrapolation in HPS relies on assumptions about the "phylogeny" of scientific practices is developed in Raphael Scholl and Samuel Schindler, "Justifying the Method of Historical Case Studies: A Phylogenetic Approach," manuscript in preparation. 50. This point was stressed for the case of generalization in biology by Bechtel, "Generalization and Discovery by Assuming Conserved Mechanisms."

51. Kinzel, "Narrative and Evidence"; Kinzel, "Pluralism in Historiography."

52. Laudan et al., "Scientific Change," 158, emphasis added. 
come out in a certain way, even though other narratives could have been told just as well, had we made different explicit or implicit prior commitments. If different authors allow their narratives to be shaped by different views of what it means to "observe" or to "detect" or to "experiment" or to "explain," then we will wind up with different historical bases against which to test theories about these practices. Robert J. Richards put this concern well:

[If] observations are permeated by theory, then the empirical world becomes rather like silly putty in the hands of a dexterous philosopher. $^{53}$

What is worse, this type of theory-ladenness may be difficult to detect. We may be able to guard against selection bias or cherry-picking by adopting methodological safeguards - for instance, by articulating clearly the criteria by which historical cases are selected. ${ }^{54}$ But the deeper permeation of historical data by philosophical concepts may be intractable because we cannot write history without taking some perspective.

Exponents of the confrontation model offer two main arguments to defuse the problem of theory-ladenness. The first is an argument from symmetry. Laudan and co-authors wrote that the problem is "a risk in all forms of empirical research" which "seems no higher here than elsewhere." 55 If the philosophy of science cannot be an empirical project because of theoryladenness, then neither can particle physics or biochemistry. But few of the participants in this debate would deny the successes of the natural sciences themselves.

The second argument points to our apparent success in overcoming theory-ladenness. For example, David Hull argued that T. H. Morgan's seminal research in genetics was a piecemeal refutation of almost every belief that Morgan initially held. Similarly, Popperian philosophers of science uncovered empirical difficulties of their views even though they were deeply committed to them. Hull concluded optimistically:

53. Robert J. Richards, "Arguments in a Sartorial Mode, or the Asymmetries of History and Philosophy of Science," PSA: Proceedings of the Biennial Meeting of the Philosophy of Science Association, 1992, 484.

54. For a proposal of this kind, see Scholl and Räz, "Towards a Methodology for Integrated History and Philosophy of Science," Section 4.

55. Laudan et al., "Scientific Change," 158. 
If our meta-level paradigms were so powerful that no observation couched in them could possibly refute them, then we would be in real trouble, but as in the case of science, students of science come up with observations about science that do not fit neatly into their own belief systems. ${ }^{56}$

In brief, we need to adopt some perspective to write history, but that perspective need not trap us. We can continue to improve our framework as conceptual and empirical difficulties present themselves. ${ }^{57}$ Of course it is not guaranteed that the revision of competing accounts will lead to their convergence. $^{58}$

Schickore suggested that although theory-ladenness is a fundamental obstacle for the confrontation model, her hermeneutic approach has the resources at least to mitigate the problem. Hermeneutics is "a procedure through which preliminary concepts and points of view and initial case judgments are brought together and modified and adjusted until a cogent account is obtained." 59 Such a process of equilibration gradually adjusts both our concepts and our historical accounts until we reach a reflective equilibrium. In her view, the "notion of theory-ladenness of historical data points to this very procedure but does not adequately capture the dynamic of the process." 60

I concur with Schickore's diagnosis. We can only accommodate theoryladenness if we give up the notion of a one-off confrontation between theory and data. However, the discussion in Section 4 has shown that scientific theory testing itself is far from a one-off process. On many current accounts, ordinary empirical inquiry is iterative. This is part of what Bechtel and Richardson tried to capture with their notion of "reconstituting the

56. Hull, “Testing Philosophical Claims About Science," 472.

57. This conclusion finds support in one of the main sources of present-day concerns about theory-ladenness: Thomas Kuhn's Structure. At the very heart of Kuhnian philosophy is the claim that paradigms enable their own rejection. Only when a paradigm has been worked out in precise detail can we begin to detect the conceptual and empirical anomalies that will lead to its demise. Kuhn wrote that "[a]nomaly appears only against the background provided by the paradigm" (see Kuhn, The Structure of Scientific Revolutions, Ch. 6). On this view, theory-ladenness is a feature, not a bug.

58. For a counterpoint to Hull's optimism, see for example Kinzel, "Narrative and Evidence," 53-55. Kinzel suggested that neutral, theory-free criteria for assessing competing accounts of an episode are usually too weak to settle serious disputes, while stronger criteria are themselves theory-laden and therefore non-neutral.

59. Schickore, "More Thoughts on HPS," 472.

60. Ibid. 
phenomena." As our empirical inquiry progresses, not only our explanans but also our explanandum may change.

However, even the hypothetico-deductive model was usually seen in terms of an iterative procedure. ${ }^{61}$ Accordingly, those who adapted that model for the study of science did not envision a singular confrontation between philosophical theory and historical data. It is true that the authors of the VPI project sometimes took singular confrontations to be significant, arguing that " $[\mathrm{m}]$ any of the theorists' claims are couched as universals and, hence, even single case-studies [...] can bear decisively on them." ${ }^{62}$ But they also took iterativity to be important, in particular in cases of theoryladenness.

For example, Laudan and co-authors wrote that they "would be the last to deny that historical research is 'theory-laden',"63 but insisted that the problem could be managed:

The conclusions to draw from the difficulties of testing are that tests must be constructed as carefully as possible, not that they should not be undertaken, and that sustained empirical tests will be needed, not just one all-or-nothing crucial test. ${ }^{64}$

The call for sustained empirical tests instead of one all-or-nothing crucial test clearly envisions an iterative procedure. Thus, Laudan and co-authors explicitly appealed to iteration as a solution to the problem of theory-ladenness (among others). Similarly, Hull did not suggest that theory-ladenness in empirical science is overcome in one go. Morgan, for example, "reported no conversion experience as he abandoned one paradigm for another." Instead, "he painfully modified one belief after another as the experiments that he and his students ran forced him to." ${ }^{\prime 65}$

It appears that most authors in this debate agree. All acknowledge the problem of theory-ladenness, and all take iterativity to be its proper remedy. In order to "weaponize" the quite general problem of theoryladenness against the confrontation model in particular, we must frame empirical inquiry in terms of a singular confrontation between theory and

61. See for instance Hempel, Philosophy of Natural Science, Chapters 2 and 3.

62. Donovan, Laudan, and Laudan, Scrutinizing Science, 13.

63. Laudan et al., "Scientific Change," 158.

64. Ibid., 158-9.

65. Hull, "Testing Philosophical Claims About Science," 471. 
data. As I have argued, this fits neither the conception of empirical inquiry of philosophical naturalists nor our most compelling recent studies of empirical inquiry in biology.

\subsection{The separation of responsibility between history and philos- ophy of science}

The confrontation model can be taken to suggest a division of labor. Philosophers provide theories to test, and historians provide the data by which they are tested. The problem is that historians may not be delivering relevant material for the philosophical project. We saw in Section 3 that Schickore surveyed winners of the Pfizer Award and concluded that their topics did not overlap with the interests of most professional philosophers of science.

Although the Pfizer Prize is not representative of the entire field of the history of science, it is probably true that current historical works rarely speak directly to current philosophical problems, and vice versa. But the chasm between the disciplines should not be exaggerated. Consider for instance both the 2007 and 2014 Pfizer Prizes, to David Kaiser and Sachiko Kusukawa, respectively, which were awarded for works on scientific visuals. This is a topic that appears to be of rapidly increasing interest to philosophers of science, who have started to think about the role of visuals in hypothesis generation, induction, explanation, and much more. ${ }^{66}$ It is not at all hard to see how historical interests and philosophical concerns might eventually connect.

Moreover, and following the theme of the present paper, the idea of a division of labor is to some extent an artifact of mid-twentieth-century philosophy of science. It closely mirrors the division of labor between theoreticians and experimentalists in physics, which philosophers of science may have taken to be a typical feature of mature sciences. But this conception does not generalize even within the sciences. It is not the norm in biology for theoreticians and experimenters to form distinct communities

\footnotetext{
66. An admittedly biology-centered selection includes Benjamin Sheredos et al., "Why Do Biologists Use So Many Diagrams?," Philosophy of Science 80, no. 5 (2013): 931-944; Daniel C. Burnston, "Data Graphs and Mechanistic Explanation," Studies in History and Philosophy of Biological and Biomedical Sciences 57 (2016): 1-12; Raphael Scholl, "Spot the Difference: Causal Contrasts in Scientific Diagrams," Studies in History and Philosophy of Biological and Biomedical Sciences 60 (2016): 77-87.
} 
(with rare exceptions). In most biological laboratories, the invention of hypotheses, their empirical test, and the theoretical interpretation of results is tightly integrated - indeed, often in the work of one person.

To be sure, this aspect of biological practice may one day change. But there is nothing about empirical inquiry per se that demands a division of labor between theoreticians and experimenters. Almost thirty years ago, Laudan wrote that "philosophers of science cannot wait for, nor should they expect, historians of science to do their work for them." ${ }^{\prime 67}$ This still seems exactly right.

\subsection{The rationale for privileging history}

In Section 3 we encountered Schickore's worry that the confrontation model cannot justify an essential role for history in the philosophy of science:

[I]f philosophy of science is recast as an empirical theory about science, the privileging of historical information over other empirical data appears utterly arbitrary. ${ }^{68}$

Her own argument for the indispensability of history to the philosophy of science embraced historicism in the sense that "understanding a concept or practice involves understanding how it came about." ${ }^{69}$ A first goal of this approach is to understand current methodological and epistemological concepts and practices by understanding their history. This is related to what James Lennox has called the "phylogenetic approach" to HPS.70 A second goal is to understand the concepts we use to analyze science by understanding their history, as well. ${ }^{71}$ I am entirely sympathetic to this

67. Laudan, “Thoughts on HPS," 13.

68. Schickore, "More Thoughts on HPS," 470.

69. Ibid., 455.

70. James G. Lennox, "History and Philosophy of Science: A Phylogenetic Approach," História, Ciências, Saúde-Manguinhos 8, no. 3 (2001): 655-669.

71. But see also Jouni-Matti Kuukkanen, "Historicism and the Failure of HPS," Studies in History and Philosophy of Science Part A 55 (2016): 3-11. Kuukkanen argued that historicism, far from being the cement that holds history and philosophy of science together, may explain the failure of HPS. On his account, historians are mostly historicists who believe that the objects of their research are impermanent, while philosophers tend to search for essential or permanent qualities of science. He suggested that this ontological tension between historicism and essentialism precluded lasting integration. But I am skeptical about both the explanans (does a majority of philosophers of science really search for essential qualities?) and the explanandum (HPS has not failed). 
historicist argument. Understanding current states and concepts by understanding how they came about is a core motivation for practicing integrated HPS. It is also entirely compatible with a naturalized philosophy of science, since genetic understanding is a core aspect of many natural sciences as well (consider astronomy, geology, or evolutionary biology).

However, Schickore exaggerated by arguing that, absent historicism, the history of science is dispensable within a naturalized philosophy of science. There are two leading arguments to that effect: First, that recent science offers a superior empirical basis for a naturalized philosophy of science; and second, that other empirical disciplines that study science offer an alternative empirical basis. On close inspection, both arguments are unsatisfactory.

The argument that recent science offers superior evidence is usually traced to Giere's "marriage of convenience" paper:

[S] urely we know (or can learn) more about the discovery of DNA than of bacteria, and surely the study of recent developments in science requires no peculiarly historical techniques or at least not the techniques now taught by most historians of science. $^{72}$

Both of Giere's main points are doubtful. First, the assumption that we have richer epistemic access to recent than to past science is intuitive, but it is an oversimplification. Our epistemic access depends on the questions we intend to study as well as the types of evidence we have at our disposal. The authors of the VPI project clearly appreciated this point in their methodological preliminaries. ${ }^{73}$ Sometimes the historical record is very rich. Charles Darwin left copious and insightful records about his reasoning not only in private notebooks but also in wide-ranging correspondence. We often possess no comparable sources from more recent scientists. To be sure, when studying contemporary science we have methods at our disposal that we lack in the study of past science. These include everything from the ethnographer's participant observation to interviews, surveys, and even experimental designs. But even when we are fortunate enough to have obtained these types of data for precisely the right scientists

72. Giere, “Intimate Relationship or Marriage of Convenience?," 290.

73. Donovan, Laudan, and Laudan, Scrutinizing Science, 8-14. 
at precisely the right time, they need not be superior to traditional historical sources. A carefully kept laboratory notebook, or a private exchange of letters, may be more revealing of some aspects of scientific practice than interviews, surveys, and even direct participation in laboratory activities. It is false to assume that recent science invariably offers richer evidence.

There are some questions to which the study of contemporary science gives us no access at all. For example, the VPI project asked questions about the role of revolutions in scientific thought. Such revolutions were taken to occur over decades and even centuries, and it is not at all clear how we could learn about them from the study of recent science alone - unless we designed and funded our studies for the seriously long run. Moreover, it seems hasty to assume that all philosophically interesting scientific practices are best instantiated in recent science. It is likely that some practices that are essential to the genesis of the existing corpus of scientific beliefs, and that are therefore philosophically salient, are absent from or underrepresented in contemporary science. If the store of philosophically interesting scientific practices is strictly cumulative, then such an intriguing finding would be the result, not the starting assumption, of a metascientific project.

Giere's second point was that the study of recent science does not rely on the techniques typical of historical studies. Unfortunately, his examples of past and recent science - the discovery of bacteria and of DNA - make it difficult to assess the claim. Both are ambiguous, since we can place the discovery of bacteria in the seventeenth century (when they were microscopically detected) or in the nineteenth (when they were named and became a crucial focus of inquiry). Similarly, nucleic acids were discovered in the nineteenth century, but the distinction between ribonucleic acid and deoxyribonucleic acid occurred only in the twentieth. Whichever dates are chosen, it is difficult to categorize either episode as "recent" from Giere's vantage point in 1973. Perhaps Giere was instead referring to Crick's and Watson's discovery of the three-dimensional structure of DNA, published in 1953. So let us stipulate generously that any science conducted in the twenty-five years before the present falls on the recent side of the continuum. I then still fail to see how its study does not rely precisely on the main technique of the historian: the critical analysis of extant written and material sources. The analysis of sources is essential, even when we are studying recent episodes to which other methods (such as interviews with 
the scientific actors themselves) are also applicable.

The second argument, which Schickore emphasized, reflects the growth of diversity in the study of science in the decades after Giere's writings:

Within naturalized philosophy, historical study becomes just one option among many other empirical approaches, such as sociology, cultural studies, cognitive science, ethnography, anthropology, media studies, and so on. ${ }^{74}$

The claim here is not that recent science offers superior epistemic access to scientific practice than past science, but that disciplines other than history offer alternative empirical bases.

Interpreted in one, somewhat restricted sense, this conclusion seems unobjectionable and even welcome. The history of science as a discipline will only be one of many contributors to a naturalized metascientific project. A more ambitious reading is that the past of science itself is dispensable as the empirical basis of a metascientific project. But this would be a category mistake. The shared empirical basis of all the naturalistic disciplines that study science is constituted by science's past up to the present moment. Psychologists and sociologists are certainly interested in different aspects of that empirical basis than historians or philosophers. If they are studying the recent past of science and science in the making, they can also use different methods in their studies. But we must not mistake a difference in interests or methods for a difference in the object of study itself. Far from offering an alternative empirical basis, these disciplines offer useful alternative concepts, questions and methods with which to approach the study of science.

If this is right, then the history of science's position as the "data" in the history-philosophy relationship is secure. However, significant extensions may be in store for philosophy's role as the source of "theory." Many of the emerging frontiers in the philosophy of science will require the adoption of concepts from other disciplines. For instance, it would be surprising if no concepts from sociology were relevant to the study of scientific epistemology in collaborative or competitive settings; or if no concepts from cognitive science were relevant to the study of the roles of scientific diagrams. This kind of opportunism and cross-fertilization is what the natu-

74. Schickore, "More Thoughts on HPS," 470. 
ralized perspective on the philosophy of science would have us expect. It it commonplace in science to import models and methods from one area to address issues in another. Consider that game theoretic models are useful both in population genetics and in economics; that PCR machines serve pathologists as well as paleogeneticists.

To sum up, we should ask the conceptual questions and use the empirical methods that are most conducive to a comprehensive metascientific project, regardless of their traditional disciplinary associations. But even though concepts and methods may originate in any of the disciplines that study science, they must all share the history of science (understood broadly) as their empirical basis.

\section{Conclusions}

Traditional models of empirical inquiry are concerned with relating particular facts to general claims, where generality is understood in terms of universally quantified statements. The "confrontation model" has adopted these models to explicate the relationship between the history and the philosophy of science. Unsurprisingly, it has therefore inherited the many difficulties of its inspirations. In Schickore's words, the model "has led to a number of unproductive debates about the nature and merits of HPS."75 I could not agree more. The confrontation model provokes debates about how many ravens must be black before we are warranted to assert that all ravens are black - or rather, about how many biological explanations must be mechanistic before we are warranted to assert that all biological explanations are mechanistic. This way of framing the history-philosophy relationship is unproductive.

Schickore diagnosed the problem to the very notion of analogizing the methodology of HPS to the methodology of the empirical sciences. However, I have argued that the basic analogy to the empirical sciences is sound. At the core of the confrontation model's difficulties is its reliance on two problematic models of inference: hypothetico-deductivism and enumerative induction.

I have reframed the confrontation model based on recent accounts of empirical inquiry in biology. On the reframed model, students of HPS

75. Schickore, "More Thoughts on HPS," 465. 
engage in a process that involves three operations. First concrete exemplars are studied, then abstract descriptions are articulated, and finally the scope of the abstract descriptions is explored by studying further concrete instances. This process illuminates what we are doing when we are investigating the nature of induction, explanation, experimentation, or of any other salient aspect of science. Importantly, our goal is not generality understood in terms of universally quantified statements. That is why the traditional, vexatious models of inductive inference, which are focused on the problem of ampliative inference, are inapplicable. Instead, the goal is to know how broadly, and in what variations, certain abstract descriptions apply to concrete instances.

Reframing the empirical methodology of HPS in this way, the two main difficulties of the traditional confrontation model can be resolved or mitigated. First, the reframing dissolves the dilemma of case studies. The dilemma asks how history and philosophy of science can be integrated either bottom-up or top-down, since in the first case we will generalize without warrant from particular historical cases, and in the second case we will be liable to use cherry-picked historical cases to confirm preferred philosophical intuitions. On the model of empirical inquiry outlined here, the dilemma does not apply, since practitioners of HPS rarely try to leverage individual historical cases in order to support general philosophical theses.

Second, the reframed confrontation model has the resources for dealing with the problem of the theory-ladenness of historical data. I argued that there is broad recognition of the problem and equally broad agreement about the appropriate remedy. It is some sort of iterative procedure that allows us to revise and adjust our conceptions in the course of inquiry. Iterativity in this sense is a feature not only of Schickore's hermeneutic methodology, but also of the traditional confrontation model and (even more emphatically) of my reframed version.

The recognition that the conceptual difficulties of the confrontation model have been exaggerated does not commit us to rejecting complementary and even alternative approaches. For example, we can embrace Schickore's or Lennox's historicism as a productive approach to integrated HPS even as we also embrace the analogy to the natural sciences. Similarly, treating parts of HPS as a science of science does not rule out that some questions are best approached using tools from the hermeneutic tradition. It would 
be surprising indeed if a single approach were optimally suited to answering all philosophical questions about science.

To conclude, practicing HPS as a science of science is both attractive (because of the conceptual appeal of a naturalized philosophy of science) and viable (because the objections to the confrontation model can be answered). However, this is not to say that being a successful empirical science is the discipline's only goal. Far from it. History and philosophy of science is also uniquely positioned to reflect broadly on the actual and desired role of science in society. Such political and societal engagement is typical of many sciences. The empirical and theoretical knowledge of physics and economics contributes to a wide range of pressing debates, from climate science to monetary policy. A robust metascience can and should play a similar role. But to be useful in that role, it must first of all be a reliable science of science.

\section{Acknowledgments}

This paper was prompted by stimulating discussions at the workshop "Testing Philosophical Theories Against the History of Science" at the University of Oulu, Finland, September 21-22, 2015. I am grateful to Katherina Kinzel and an anonymous referee for their feedback on an earlier version of the manuscript, and to Jouni-Matti Kuukkanen for his editorial patience. This work was partly supported by the Swiss National Science Foundation (grant number P300P1_154590). 